\title{
Research on Schedule Management of Shipyard Based on Task Package
}

\author{
Ke Gao, Xiaoping Ma
}

\begin{abstract}
To solve the problem of how to effectively manage the progress of the ship during the ship construction process. Based on the task package, this paper analyzes and studies the shipyard operation schedule management method, and focuses on the schedule planning process and schedule management method based on the task package construction process to achieve the full process management of the ship's operation progress. Finally, effective control over the deviation of the ship construction schedule will be realized to ensure delivery on time.
\end{abstract}

Index Terms - Progress control; planning; earned value method

\section{INTRODUCTION}

With the development of ship production technology, the requirement for ship performance is getting higher and higher, so the process of ship construction is becoming more and more elaborate and complex. On the premise of ensuring the quality and cost of ship products, it becomes very important to manage the progress of ship construction work effectively. Task package, as a basic operation unit in ship production management, is the key factor to guide ship construction and production. Based on the task package, this paper studies the process of ship schedule planning and the method of schedule control in the process of operation and construction, and uses the network planning technology and earned value method to manage shipyard operation schedule, which improves the timeliness and effectiveness of shipyard operation schedule control $^{[1]}$.

\section{TASK PACKAGE BASED SCHEDULE PLANNING}

The shipyard operation schedule is the basic basis for schedule management during the construction process. The task package-based shipyard operation schedule preparation steps include: task package operation decomposition and task assignment, task package logic sequencing, task package time prediction, task package time parameter calculation, and development of ship operation schedule.

\section{A. Job decomposition and task assignment of task packages}

1) Task package job decomposition

Decomposition of ship construction operations should be based on two dimensions: vertical and horizontal. The horizontal decomposition corresponds to the ship construction progress. According to the key nodes such as start-up, docking, launching, sea trial, and delivery, the ship construction process is divided into The first operation, the dock (set) loading operation and the rear operation, in each time schedule, combined with the ship construction work

Ke Gao, Xiaoping Ma, School of Naval Architecture \& Ocean Engineering, Jiangsu University of Science and Technology, Zhenjiang, Jiangsu, China. process to complete the corresponding task package operation; the ship construction operation is divided vertically by the construction order of the intermediate product. In combination with the shipyard's production organization, different shell coating operations are carried out in layers according to WBS elements, activities, task packages, and dispatching orders, and the tasks of decomposition are distributed to the production line for guidance.

The main planned work items in the production schedule are production activities. The task package is the basic operation unit formed according to different production areas, work stages and job types. The work order is the daily breakdown of the task package. Job unit. The core of the ship engineering operation decomposition is to reasonably decompose the ship construction process and get a task package to guide the on-site production.

As the basic unit of work for on-site production, the task package contains not only the detailed work content, but also the production resource information necessary to meet the production of the task package. A reasonable task package should contain the following information: what part of the job, what type of job, what stage of the job, and what skills are needed to complete the job. The basic composition of the task package is shown in the figure 1 .

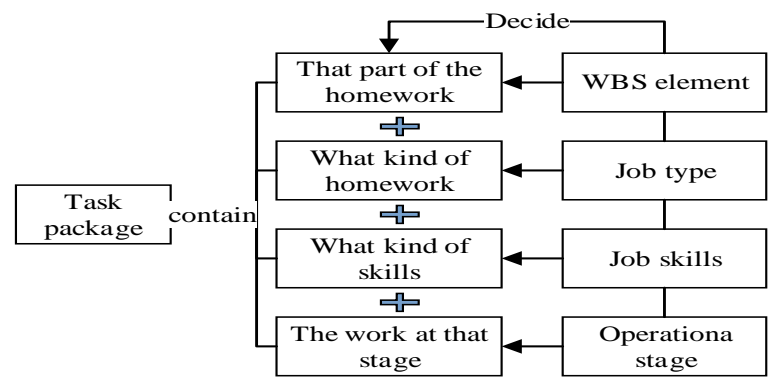

Fig.1 Task package basic composition

\section{2) Task Assignment}

On the basis of the decomposition of the shipbuilding operation, in order to clarify the responsibility of the production department and the construction team during the construction process, it is convenient for the progress control department to carry out effective coordination of the progress control during the shipbuilding process, and the later accountability must be Conduct effective division of responsibilities, clarify responsible departments and responsible teams, form a responsibility distribution matrix, implement tasks and responsibilities at all levels of the engineering breakdown structure, and effectively integrate technology and management.

\section{B. Task package logic sort}

The task package logic sorting is simply based on the task 
package decomposition, based on the ship construction process, combined with the production relationship between the task packages for production sequencing. There are four general logical relationships between task packages, and other logical relationships can be evolved through these four relationships. Define task A as the immediate task, task B as the immediate task, the immediate task as the activity in front of the non-start task, and the immediate task as the task behind the task. In the management of ship mission planning, "FS" is the most common task logic relationship, and "SF" is rarely used in ship projects. The definition of these logical relationships is shown in the figure.

\begin{tabular}{|c|c|c|c|c|}
\hline Types & Relationship & Correlation & $\begin{array}{c}\text { Relationship } \\
\text { definition }\end{array}$ \\
\hline $\begin{array}{c}\text { Finished to the } \\
\text { beginning } \\
\text { (FS) }\end{array}$ & Serial & Related & $\begin{array}{c}\text { Only the logical relationship } \\
\text { that can be started } \\
\text { immediately after the task is } \\
\text { completed }\end{array}$ \\
\hline $\begin{array}{c}\text { Completed to } \\
\text { completion (FF) }\end{array}$ & parallel & irrelevant & $\begin{array}{c}\text { The logical relationship that can } \\
\text { be completed only after the task } \\
\text { is completed immediately. }\end{array}$ \\
\hline $\begin{array}{c}\text { Start to start (SS) } \\
\text { Start to finish } \\
\text { (SF) }\end{array}$ & parallel & irrelevant & $\begin{array}{c}\text { Only the logical relationship } \\
\text { between the start of the task } \\
\text { and the start of the task }\end{array}$ \\
\hline coupling & Related & $\begin{array}{c}\text { Only the logical relationship } \\
\text { that can be completed } \\
\text { immediately after the start of } \\
\text { the task }\end{array}$ \\
\hline
\end{tabular}

Fig.2 This task package logic definition

\section{Task contract time forecast}

Task contract time is the amount of time a task spends from start to finish under conditions that determine resources. Usually the task contract time forecast includes the task package standard work time and target work time. The standard working hours are the construction time required to complete the task under the ideal situation (complete production resources) without considering the work hours, such as lost work hours, supplementary work hours, etc.; the target working hours are actual planned working hours including invalid working hours. Usually, the target working hours should be formulated in consideration of the production time and the unexpected work time that may occur during the construction process.

There are many methods for predicting the standard working hours of task packages. The direct statistics method and the three-point estimation method are commonly used.

(1) Direct statistical method is the labor time required by the shipyard statistics to represent the average working level of the shipyard in the normal resource allocation. The average working hours of the task is calculated according to the statistics, which is the standard working time of the task.

(2) The three-point estimation method calculates the time required for the task to be completed from three angles, the most optimistic time $\left(\mathrm{t}_{\mathrm{o}}\right)$, the most pessimistic time $\left(\mathrm{t}_{\mathrm{p}}\right)$, and the most likely time $\left(t_{m}\right)$, combined with the weights of the three times. Find the average work time required for this task. There are two commonly used calculation formulas for the three-point estimation method as follows in equation (1) and (2):

Beta distribution: $T_{e}=\left(t_{o}+4 t_{m}+t_{p}\right) / 6$

Triangle distribution: $T_{e}=\left(t_{o}+t_{m}+t_{p}\right) / 3$
The target working hours are based on the allocation of on-site resources and the time allocated to the task package in combination with the production plan, which is the basis for planning. The target working hours are generally greater than the standard working hours, and the target working hours are calculated by dividing the standard working hours by the time working rate. In general, the time rate of new ships will be less than 1 , but with the increase in construction proficiency and the construction of a series of ships, the time rate will be infinitely close to 1 . Therefore, in the actual production process, it is necessary to modify the time utilization rate according to different shipbuilding projects under construction to ensure the accuracy of the target working hours.

\section{Task package time parameter calculation}

During the construction of the ship, the construction sequence between the tasks is fixed, and the start and end time of each task is related to the start and end time of the previous task. Therefore, according to the duration of the project, the project planning should be based on the duration of the project. Time parameters related to each task package. This paper takes the single-code network diagram as an example to describe the calculation rules of the task package time parameters

1) jet lag

(1) The total time difference of task i refers to the maximum time allowed for the task to be postponed without affecting the total construction period of the project. The total time difference of the task package can be used to optimize the network plan. Usually expressed in $\mathrm{TF}_{\mathrm{i}}$, calculated as shown in equation (3):

$\mathrm{TF}_{\mathrm{i}}=\min \left\{\mathrm{TF}_{\mathrm{j}}+\mathrm{LAG}_{\mathrm{i}-\mathrm{j}}\right\}$ (3) Where $\mathrm{LAG}_{(\mathrm{i}-\mathrm{j})}$ is the time interval between two $\mathrm{i}$ and $\mathrm{j}$ tasks. When task $\mathrm{i}$ is the project end task, the total time difference of task $i$ is equal to the difference between the planned duration and the calculated duration.

(2) Mission free time difference refers to the maneuver time that can be utilized by the task without affecting the earliest start time of the task. Usually expressed in $\mathrm{FF}_{\mathrm{i}}$, calculated as shown in equation (4):

$$
\mathrm{FF}_{\mathrm{i}}=\min \left\{\mathrm{LAG}_{\mathrm{i}-\mathrm{j}}\right\}
$$

When task $\mathrm{i}$ is the project end task, it is equal to the difference between the planned duration $T_{p}$ and the earliest completion time $\mathrm{EF}_{\mathrm{i}}$ of the task. Calculated as shown in equation (5):

$$
\mathrm{FF}_{\mathrm{i}}=\mathrm{T}_{\mathrm{p}}-\mathrm{EF}_{\mathrm{i}}
$$

2) In the single-code network diagram, Di represents the duration of task $i$, and $D_{j}$ represents the duration of the previous task. The task package i earliest start time $\mathrm{ES}_{\mathrm{i}}$, task package i latest start time LSi, task package i earliest end time $\mathrm{EF}_{\mathrm{i}}$, task package i latest end time $\mathrm{LF}_{\mathrm{i}}$ calculation rules are as follows:

(1) The earliest start time of task i refers to the time when the task is completed, the time when the task is first started, usually expressed by $\mathrm{ES}_{\mathrm{i}}$, calculated as shown in equation (6):

$$
\mathrm{ES}_{\mathrm{i}}=\max \left\{\mathrm{ES}_{\mathrm{j}}+\mathrm{D}_{\mathrm{j}}\right\}
$$

(2) The earliest completion time of task i refers to the time when the task is completed, the time when the task is completed at the earliest, usually expressed by $\mathrm{EF}_{\mathrm{i}}$, calculated as shown in equation (7): 


$$
\mathrm{EF}_{\mathrm{i}}=\mathrm{ES}_{\mathrm{i}}+\mathrm{D}_{\mathrm{i}}
$$

(3) The latest start time of task i refers to the latest time when the task must be started without affecting the task and project duration. Usually expressed in $\mathrm{LS}_{\mathrm{i}}$, the calculation is as shown in equation (8)and (9):

$$
\mathrm{LS}_{\mathrm{i}}=\min \left\{\mathrm{LF}_{\mathrm{i}}-\mathrm{D}_{\mathrm{i}}\right\}
$$

$\mathrm{LS}_{\mathrm{i}}=\mathrm{ES}_{\mathrm{i}}+\mathrm{TF}_{\mathrm{i}}$ time for task i refers to the latest time at which the task must be completed without affecting the project duration.

Usually expressed in $\mathrm{LF}_{\mathrm{i}}$, calculated as shown in equation (10)and (11):

$$
\begin{gathered}
\mathrm{LF}_{\mathrm{i}}=\mathrm{LS}_{\mathrm{i}}+\mathrm{D}_{\mathrm{i}} \\
\mathrm{LF}_{\mathrm{i}}=\mathrm{EF}_{\mathrm{i}}+\mathrm{TF}_{\mathrm{i}}
\end{gathered}
$$

\section{E. Prepare ship operation schedule}

On the basis of the above work, the operation schedule is calculated by measuring the quantity of the project package, calculating the demand for production resources and labor, determining the order, duration and related time parameters of each task package, which are reflected in the form of progress performance. As the basis for controlling the progress of construction work. A reasonable ship operation schedule shall include at least the following contents: Decompose the ship construction process, clarify and explain the production tasks of the monthly target, the node target and the final target in the ship construction process, and clarify the main body of each task; The task packages in the task are logically sorted to determine the task production sequence; the human resources and working hours required to complete the task package are clarified; the relevant network planning time parameters are calculated; and the production capacity and human load are comprehensively reviewed.

On the basis of the above-mentioned project-based production materials, the project planner begins the task package planning work. The planning process is as follows in the figure 3:

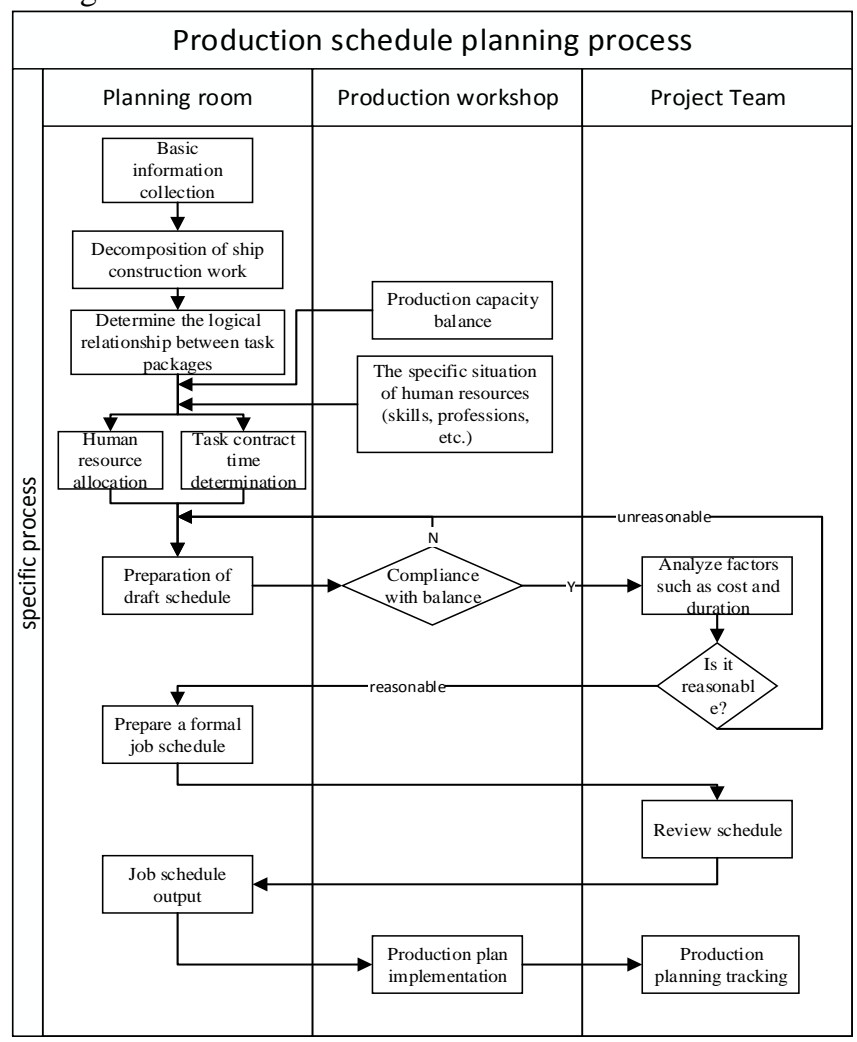

Fig.3 Planning flow chart

\section{F. Shipyard operation schedule optimization}

After the completion of the ship operation schedule, the planner must compare the work time data of the previous historical ship type and adopt different optimization plans according to the deviation. Since the multi-projects are operated in parallel during the construction of the ship, it is necessary to consider the manpower load of the construction department in the task arrangement, and ensure that the production load of all the projects cannot exceed the total production capacity of the workshop, and ensure that the plan is balanced and reasonable. The ship operation schedule is mainly based on three aspects of construction period, cost and resources. The ship operation plan should achieve the goal of rationally arranging production resources while meeting the construction cycle to achieve reasonable resource consumption and optimal economic benefits.

\section{MANAGEMENT OF SHIPYARD OPERATION PROGRESS PROCESS BASED ON TASK PACKAGE}

The ship construction operation schedule is the basis and basis for the orderly construction of the ship. However, due to the long construction period of the ship and the complicated process, there are a lot of uncertain factors affecting the schedule during the construction process, which requires us to build the ship during the construction process. It is necessary to closely track and monitor the implementation of the schedule, timely feedback the actual progress information, identify the progress deviations during the construction process, analyze the reasons for the schedule deviation, and take effective adjustment measures to ensure that the ship can deliver on time.

\section{A. Principle of earned value}

The Earned Value Method, also known as the Deviation Analysis Method, is a comprehensive and effective monitoring method for measuring project schedule and cost status in the project management field. The earned value method is based on the decomposition of the project WBS, and determines its planned construction period, cost budget and progress according to the project construction schedule. The inspection node passes the analysis of the planned cost $\mathrm{EV}$ of the completed mission package, the actual cost of the completed task AC and The planned cost of the planned task is PV. According to the four evaluation indicators, the progress deviation and cost deviation of the project are presented, and feasible prediction and adjustment measures

\begin{tabular}{|c|c|c|c|}
\hline $\begin{array}{l}\text { Indicator } \\
\text { type }\end{array}$ & $\begin{array}{l}\text { Indicator } \\
\text { name }\end{array}$ & Calculation formula & Judging criteria \\
\hline \multirow{2}{*}{$\begin{array}{l}\text { Progress } \\
\text { evaluation } \\
\text { indicator }\end{array}$} & $\begin{array}{l}\text { Progress } \\
\text { deviation SV }\end{array}$ & $S V=E V-P V$ & $\begin{array}{ll}<0 & \text { Progress lag } \\
>0 & \text { Progress ahead } \\
=0 & \text { Smooth progress }\end{array}$ \\
\hline & $\begin{array}{l}\text { Progress } \\
\text { Performance } \\
\text { Index SPI }\end{array}$ & $\mathrm{SPI}=\mathrm{EV} / \mathrm{PV}$ & $\begin{array}{l}>1 \text { Progress ahead } \\
=1 \text { Smooth progress }\end{array}$ \\
\hline \multirow[t]{2}{*}{$\begin{array}{l}\text { Cost evaluation } \\
\text { indicator }\end{array}$} & $\begin{array}{c}\text { Cost } \\
\text { deviation } \mathrm{CV}\end{array}$ & $\mathrm{CV}=\mathrm{EV}-\mathrm{AC}$ & $\begin{array}{ll}<0 & \text { Cost overrun } \\
>0 & \text { saving cost } \\
=0 & \text { Cost is flat } \\
<1 & \text { Cost overrun }\end{array}$ \\
\hline & $\begin{array}{c}\text { Cost } \\
\text { performance } \\
\text { index CPI }\end{array}$ & $\mathrm{CPI}=\mathrm{EV} / \mathrm{AC}$ & $\begin{array}{ll}>1 & \text { saving cost } \\
=1 & \text { Cost is flat }\end{array}$ \\
\hline
\end{tabular}
are proposed ${ }^{[2-4]}$. The calculation formulas and criteria for the four evaluation indicators are shown in the following table1:

Tab.1 Basic parameters of earned value method 


\section{B. Pre-control deviation analysis of ship construction schedule}

\section{1) Basic variable collection}

The earned value method must accurately measure the $\mathrm{EV}, \mathrm{PV}$ and $\mathrm{AV}$ of the task package, calculate the progress performance indicators based on the three basic variables, analyze the deviation according to the performance indicators, and take effective corrective measures.

\section{(1) Determination of planned costs}

PV is the benchmark for project schedule control. The planned cost $\mathrm{PV}$ is determined by combining the task package schedule and cost plan that have been prepared in the shipbuilding preparation phase, and the cumulative value of the total labor cost of the task package that should pass the quality inspection before the specified inspection node summarizes all the time nodes. In general, the planned labor cost for a single task package is the planned work time multiplied by the planned unit price.

\section{(2) Determination of earned value}

The EV calculation is based on the project schedule and cost budget. The planned cost statistics of the workloads that have passed the quality acceptance of all task packages at the specified monitoring points are independent of the actual labor hours and other additional costs. In the ship construction process, the calculation of earned value is usually carried out by using the percentage method of completion, 0/100 method, and two-point measurement method.

\section{(3) Determination of actual cost}

$\mathrm{AV}$ is the actual cost of all task packages when it arrives at a certain detection node, including normal planned costs, costs due to production changes, and additional costs incurred by the work. The accurate actual cost AV is very important for the accuracy of the earned value analysis. Special management personnel should be set to count the actual cost of the task package labor costs.

\section{2) Schedule deviation analysis}

Based on the collected basic variables, the relevant calculation method of earned value theory is used to analyze the progress of shipbuilding operations, identify deviations, take effective corrective measures to ensure the construction period, and dynamically predict the completion period. The deviation analysis using the earned value method in the ship construction process can be summarized as shown in the figure 4:

In the progress deviation analysis, we also need to distinguish whether the schedule deviation occurs in the critical path or the non-critical path. For the progress deviation occurring on the critical path, regardless of the deviation, it will have an impact on the ship construction period, and measures need to be taken to compensate for the deviation; When the schedule deviation occurs in the non-critical path, the degree of influence on the project duration should be analyzed according to the relationship between the deviation, the total time difference and the free time difference, and different control measures are taken according to the analysis results.

\begin{tabular}{|c|c|c|}
\hline$S$ curve & $\begin{array}{l}\text { Parameter } \\
\text { relationship }\end{array}$ & $\begin{array}{c}\text { Deviation } \\
\text { analysis }\end{array}$ \\
\hline${ }^{\operatorname{cost}} \uparrow \begin{array}{l}i \\
1 \\
1\end{array}$ & $\begin{array}{l}\mathrm{AC}>\mathrm{EV}>\mathrm{PV} \\
\mathrm{CV}<0 \quad \mathrm{SV}>0\end{array}$ & $\begin{array}{l}\text { Lagging behind schedule, } \\
\text { cost overrun, inefficiency }\end{array}$ \\
\hline$\underset{\text { time }}{\stackrel{\mathrm{EV}}{\mathrm{PV}}}$ & $\begin{array}{l}\mathrm{PV}>\mathrm{AC}>\mathrm{EV} \\
\mathrm{CV}<0 \quad \mathrm{SV}<0\end{array}$ & $\begin{array}{l}\text { Lagging behind schedule, } \\
\text { cost reduction, and low } \\
\text { efficiency }\end{array}$ \\
\hline$\underset{\text { time }}{\stackrel{\mathrm{AC}}{\mathrm{PV}}}$ & $\begin{array}{l}\mathrm{PV}>\mathrm{EV}>\mathrm{AC} \\
\mathrm{CV}>0 \quad \mathrm{SV}<0\end{array}$ & $\begin{array}{l}\text { Lagging behind schedule, } \\
\text { cost reduction, and high } \\
\text { efficiency }\end{array}$ \\
\hline 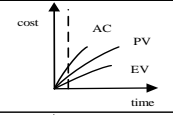 & $\begin{array}{l}\mathrm{AC}>\mathrm{PV}>\mathrm{EV} \\
\mathrm{CV}<0 \quad \mathrm{SV}<0\end{array}$ & $\begin{array}{l}\text { Lagging behind schedule, } \\
\text { cost overrun, high efficiency }\end{array}$ \\
\hline$\underset{\text { time }}{\stackrel{\text { cost }}{\longrightarrow}}$ & $\begin{array}{l}\mathrm{EV}>\mathrm{PV}>\mathrm{AC} \\
\mathrm{CV}>0 \quad \mathrm{SV}>0\end{array}$ & $\begin{array}{l}\text { Progress ahead, reduction in } \\
\text { investment, high efficiency }\end{array}$ \\
\hline 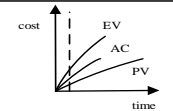 & $\begin{array}{l}\mathrm{EV}>\mathrm{AC}>\mathrm{PV} \\
\mathrm{CV}>0 \quad \mathrm{SV}>0\end{array}$ & $\begin{array}{l}\text { Progress ahead, investment } \\
\text { overrun, high efficiency }\end{array}$ \\
\hline
\end{tabular}

Fig.4 Overview of deviation analysis

3) Pre-control and corrective measures for ship construction schedule

When the progress is deviated, we must take effective measures to correct the progress in time. The commonly used methods are:

(1) Strengthen investment in production resources and human resources. When the progress is deviated, it is necessary to ensure that the materials of the subsequent processes arrive in time, and increase the input of equipment and skilled workers to compensate for the progress deviation.

(2) Improve the technical process. Scientific analysis of the actual construction conditions, mining technology potential, optimizing technical solutions, and adjusting construction procedures to make construction operations more scientific and reasonable.

(3) Rational use of existing resources to improve work efficiency and speed up progress. Reduce the invalid circulation time and waiting time, fully utilize the manpower and equipment of the entire construction process to maintain and improve the coordination and continuity of the construction process, and reduce the invalid operation time to make up the progress.

4) Ship construction period / cost forecast

Based on the current schedule performance and cost performance, we can predict the total construction period and cost of the shipbuilding project, and help the project manager to control the ship construction progress as a whole, avoiding schedule overdue and cost overrun.

There are three ways to predict the duration:

(1) Assume that the remaining work is constructed according to the current progress performance. The total duration of the task package is the total contract period OPDX divided by the current performance indicator of the current task package. The formula is as shown in equation (12):

$$
\mathrm{ETTC}=\mathrm{OPD} / \mathrm{SPI}
$$

(2) Assume that the remaining work is continued according to the previous schedule. The total duration of the task package is the previous consumption date plus the remaining workload. The original planned duration is as shown in equation (13): 
$\mathrm{ETTC}=$

Early consumption period +

Remaining workload original planned duration

(13)

(3) The mission plan has a large deviation, which causes the project management personnel to estimate the remaining work period. The total duration of the task package is the previous consumption date plus the new estimated remaining construction period. The formula is as shown in equation (14):

\section{$\mathrm{ETTC}=$}

Early consumption period +

New estimated remaining period

(14) There are three differences in cost forecasting methods:

(1) Assume that the remaining work is built according to the current cost performance. The total cost of the task package is the total planned cost BAC_X divided by the cost performance indicator of the current task package. The formula is as shown in equation (15):

\section{$\mathrm{EAC}=\mathrm{EAC} / \mathrm{CPI}$}

(2) Assume that the remaining work continues to be performed according to the remaining cost of the previous cost budget. The total cost of the task package is the actual cost of the previous period plus the remaining workload. The original plan cost formula is as shown in equation (16):

\section{$\mathrm{EAC}=\mathrm{ACWP}+(\mathrm{BAC}-\mathrm{BCWP}) \quad(16)$}

(3) When the cost of the task package changes significantly, the project manager re-estimates the cost of the remaining work. The total cost of the task package is the actual cost of the previous period plus the remaining estimated work cost. The formula is as shown in equation (17):

$\mathrm{EAC}=\mathrm{ACWP}+\mathrm{New}$ estimated remaining work expenses (17)

\section{CONCLUSION}

The ship construction process is complex and the cycle is long, and the actual progress and planning progress often deviate. We must adopt a scientific and effective management method for the ship construction schedule, and ensure that the ship can deliver the ship on time under the established resource constraints. Through the planning of the task package, establish a progress benchmark, use the earned value method to control the operation process, and control the whole process of the ship construction progress before, during and after the event.

\section{REFERENCE}

[1] Guo Jian, Wei Fajie. Research on Earned Value Management of Foreign Projects and Its Enlightenment to China[J]. Productivity Research, 2007(16): 102-103+110.

[2] Yang Xiaoli. Application Research of Progress Management in Construction Engineering Management $[\mathrm{J}]$. Building Materials and Decoration, 2019 (07): 173-174.

[3]Yang Mingxia. Application of Earned Value Method in Progress Control of Petroleum Engineering Projects[J]. Engineering Construction and Design, 2016(17): 197-199.

[4] Wang Yadong. Application of Earned Value Method in Cost Control of Construction Project Construction Stage[J]. Industry and Technology Forum, 2018, 17(01): 74-75.
Ke Gao, School of Naval Architecture \& Ocean Engineering, Jiangsu University of Science and Technology, Zhenjiang, Jiangsu, China

Xiaoping Ma, Professor, School of Naval Architecture \& Ocean Engineering, Jiangsu University of Science and Technology, Zhenjiang, Jiangsu, China 